\title{
Recommendations on quantities, symbols and measurement units for publications in ACQUAL: preparation of tables and graphs
}

\author{
W. Richter
}

Received: 21 November 2010/Accepted: 27 November 2010/Published online: 15 December 2010

(C) Springer-Verlag 2010

Tables and graphs play a significant role in the presentation of scientific ideas and results and should therefore be prepared with particular care. In addition to the instructions for authors provided on the journal's website at www.springer.com/journal/00769, the following examples are intended to give guidance for the preparation of tables and graphs.

In these examples, the same information is displayed as Table 1 and as graph (Fig. 1). One of both will usually be sufficient the more so as redundancy is undesirable.

Figures together with the captions should be selfexplaining and understandable without reference to the text. For tabulating the values of quantities and labelling the axes of graphs, it is advantageous to use the quotient of the quantity and its unit, so that the values to be tabulated or displayed are numerical values, as shown in the table and graph. The names of the quantities, preceding the quotients, support comprehension. In the case of composed units (e.g. nmol $\mathrm{L}^{-1}$ or $\mathrm{nmol} / \mathrm{L}$ ), parentheses are necessary to avoid ambiguity.

If the quantity value is expressed in $\%$, for example the mass fraction $w$, the corresponding notation ' $w / \%$ ' is, however, not recommended. Instead, ' $w(\%)$ ' should be used.

In table headings, the quotients or units should be placed in the same line(s) in all columns, as shown, for optimal readability.

If additional information is displayed in the graph, for example equations, care should be taken that the quantity symbols are written in italics.

W. Richter ( $\square)$

Braunschweig, Germany

e-mail: wolfgang.k.richter@t-online.de
Table 1 Instrument reading $I$ as a function of the amount-of-substance concentration $c$ of lead in water

\begin{tabular}{ll}
\hline $\begin{array}{l}\text { Instrument reading } \\
I / \mathrm{mA}\end{array}$ & $\begin{array}{l}\text { Amount-of-substance concentration } \\
c /(\mathrm{nmol} / \mathrm{L})\end{array}$ \\
\hline 0.113 & 1.69 \\
0.225 & 4.03 \\
0.346 & 6.12 \\
0.448 & 8.71 \\
0.583 & 11.23 \\
\hline
\end{tabular}

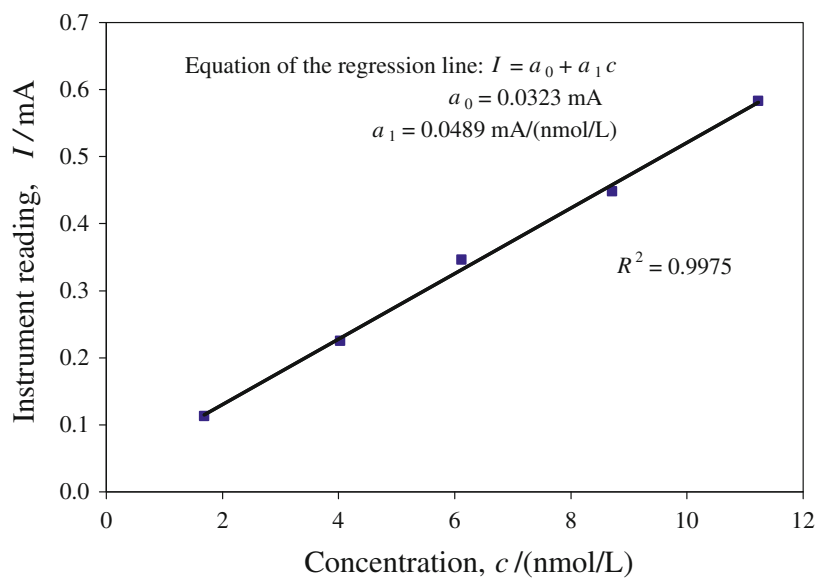

Fig. 1 Spectrometer calibration curve: instrument reading $I$ as a function of the amount-of-substance concentration $c$ of lead in water, displayed as linear regression line. $R$ is the sample correlation coefficient, $R^{2}$ the coefficient of determination 